\title{
Effect of tonicity of nebulised colistin on chest tightness and pulmonary function in adults with cystic fibrosis
}

\author{
Mary E Dodd, Janice Abbott, Julie Maddison, A James Moorcroft, A Kevin Webb
}

\begin{abstract}
Background - Inhalation of hypertonic nebulised colistin causes chest tightness and is a reason for discontinuing the treatment. This study examines the relationship of chest tightness and change in lung function in response to the inhalation of a range of tonicities of nebulised colistin and their influence on patients' preference.

Methods - Twenty seven adult patients with cystic fibrosis and a mean forced expiratory volume in one second $\left(\mathrm{FEV}_{1}\right)$ of $54 \%$ predicted (range $24-98$ ) were studied. They inhaled a nebulised solution of hypertonic, isotonic, and hypotonic colistin over three consecutive days in random order in a double blind fashion. Measurements of chest tightness, using a visual analogue scale (VAS), and $\mathrm{FEV}_{1}$ were recorded before and $0,15,30,60$, and 90 minutes following inhalation. The solution preferred by each patient was determined at the end of the three days.
\end{abstract}

Results - All tonicities caused a significant fall in $\mathrm{FEV}_{1} \%$ predicted and an increase in chest tightness, with no differences between the solutions. However, the mean (SE) time to the maximum fall in $\mathrm{FEV}_{1} \%$ predicted was significantly different between the solutions (hypertonic 7.8 (2.1) min, isotonic 19.2 (5.5) $\mathrm{min}$, and hypotonic $34.2(5.9) \mathrm{min}$ ) with a mean difference $(95 \%$ CI) between hypotonic and hypertonic solutions of 28.04 (14.6 to 41.5) min, between isotonic and hypertonic solutions of $\mathbf{1 2 . 0}$ ( -0.1 to 24.1 ) $\mathrm{min}$, and between hypotonic and isotonic solutions of 15.6 (1.8 to 29.4) min. Positive correlations existed for the maximum fall in $\mathrm{FEV}_{1} \%$ predicted between the hypertonic and isotonic solutions $(r=0.62, \mathrm{p}<0.001)$ and between the hypotonic and isotonic solutions $(r=$ $0.64, \mathrm{p}<0.001)$. There was no correlation between the objective and subjective measurements for any solution. The patients' preference varied.

Conclusions - All tonicities of colistin caused equal symptoms of chest tightness and reduction in pulmonary function. It is recommended that the patient is challenged with nebulised colistin before prescription of the drug and that the challenge is preceded by an inhaled bronchodilator. Most of the patients preferred the isotonic or hypotonic solutions. The isotonic solution reflects a fall in $\mathrm{FEV}_{1}$ representative of all the solutions. The fall in $\mathrm{FEV}_{1}$ to the hypotonic solution occurred over a longer period and may be better tolerated by some patients.

(Thorax 1997;52:656-658)

Keywords: tonicity, nebulised colistin, cystic fibrosis.

The benefits of nebulised antibiotics in cystic fibrosis include a reduction in the rate of decline of lung function and in the number of hospital admissions for patients with severe disease, ${ }^{1}$ a reduction in positive sputum cultures in patients recently colonised with Pseudomonas aeruginos $a,{ }^{2}$ and eradication of the organism. ${ }^{3}$ Colistin sulphomethate, a polymyxin antibiotic, may be the drug of choice because resistance is uncommon ${ }^{4}$ and it is the only antibiotic licensed for inhalation in the UK. Hypertonic nebulised antibiotics including colistin can induce bronchoconstriction in patients with cystic fibrosis ${ }^{256}$ even when the treatment is preceded by inhalation of a bronchodilator. Bronchoconstriction may be a reason for poor compliance and discontinuing the therapy. ${ }^{5}$ Previous work has shown that immediately perceived benefits or adverse symptoms influence compliance with treatment. ${ }^{7}$ A subject's perception of chest tightness may differ from objective measurements ${ }^{89}$ and therefore might influence compliance irrespective of objective changes in lung function.

Colistin is a dry powder formulation requiring reconstitution with sterile water or $0.9 \%$ sodium chloride before aerosol inhalation. The choice of solvent will influence the tonicity of the solution. In asthmatic patients hypertonic and hypotonic solutions induce bronchoconstriction to a greater degree than isotonic solutions. ${ }^{10}$ Hypotonic and isotonic solutions of colistin have not previously been studied in patients with cystic fibrosis.

The aims of this study were to examine the relationship between the objective measurement of lung function and the subjective measurement of chest tightness and their influence on patients' preference in response to hypotonic, isotonic, and hypertonic solutions of nebulised colistin. We hypothesised that isotonic nebulised colistin would not induce bronchoconstriction and would be the treatment preferred by the patients.

\section{Methods}

PATIENTS

Thirty adult patients (23 men) with cystic fibrosis participated in the study when they were 
Table 1 Differences in mean values (95\% CI) for maximum fall in $F E V_{1}$ (\% predicted) and maximum change in VAS (\%) between the solutions

\begin{tabular}{lccc}
\hline & $\begin{array}{c}\text { Maximum fall in FEV } \\
(\% \text { predicted) }\end{array}$ & Difference & $95 \% C I$ \\
\hline Hypertonic $v$ isotonic & $7.2 v 6.4$ & 0.77 & -0.85 to 2.4 \\
Hypertonic $v$ hypotonic & $7.2 v 5.5$ & 1.60 & -0.41 to 3.6 \\
Isotonic $v$ hypotonic & $6.4 v 5.5$ & 0.85 & -0.37 to 2.0 \\
& Maximum change & & \\
& in VAS $\%$ ) & -4.3 & -13.6 to 5.0 \\
Hypertonic $v$ isotonic & $6.6 v 10.8$ & -2.0 & -9.5 to 5.5 \\
Hypertonic $v$ hypotonic & $6.6 v 8.6$ & 2.3 & -3.1 to 7.7 \\
Isotonic $v$ hypotonic & $10.8 v 8.6$ & & \\
\hline
\end{tabular}

judged to be clinically stable. Details of bronchodilator and inhaled steroid use were recorded. Patients were recruited on their willingness to take part and were chronically colonised with Pseudomonas aeruginosa.

\section{STUDY DESIGN}

On each study day oral and inhaled bronchodilators were withheld for 12 hours. Chest clearance was performed prior to the baseline measurements of a visual analogue scale (VAS) score of chest tightness and forced expiratory volume in one second $\left(\mathrm{FEV}_{1}\right)$ using a dry bellows spirometer (Vitalograph Ltd, UK). The patients then inhaled $4 \mathrm{ml}$ of either a hypertonic, isotonic, or hypotonic solution of colistin on three consecutive days at the same time of day. The study was randomised and double blind. All solutions were delivered using a Sidestream nebuliser with a mouthpiece and CR60 compressor (Medic-Aid, Pagham, Sussex, UK). The VAS score and $\mathrm{FEV}_{1}$ were repeated immediately and $15,30,60$, and 90 minutes after nebulisation. At the end of the three-day study period the patients were asked to indicate which solution they preferred to inhale (day 1 , day 2 , day 3 or no preference).

TONICITY OF COLISTIN

Solutions of colistin which were easily reconstituted for home use (two million units (MU) dissolved in $4 \mathrm{ml}$ solvent) were analysed for tonicity by the Department of Biochemistry. The osmolality of $2 \mathrm{MU}$ colistin in $4 \mathrm{ml} 0.9 \%$ sodium chloride was $417 \mathrm{mmol} / \mathrm{kg}$ (hypertonic), of $2 \mathrm{MU}$ colistin in $2 \mathrm{ml} 0.9 \%$ sodium chloride plus $2 \mathrm{ml}$ sterile water was $264 \mathrm{mmol} /$ $\mathrm{kg}$ (isotonic), and of $2 \mathrm{MU}$ colistin in $4 \mathrm{ml}$ sterile water was $150 \mathrm{mmol} / \mathrm{kg}$ (hypotonic).

\section{STATISTICAL ANALYSIS}

Analyses of variance and paired $t$ tests were employed to compare baseline data between the three solutions, to analyse the maximum changes in $\mathrm{FEV}_{1}$ and VAS scores between the values before and after drug administration, and to compare the time to the maximum fall between the solutions. Correlation coefficients between variables were calculated using the Spearman's rank procedure. The $\chi^{2}$ test was used to examine solution preference. For the purpose of analysis all $\mathrm{FEV}_{1}$ values are expressed as a percentage of predicted values ${ }^{11}$ and the VAS score as the percentage distance moved along the line.

\section{Results}

Twenty seven patients (20 men) completed the study; two were withdrawn because their baseline measurements failed to fall within 15\% of day 1, and one further patient withdrew. The mean age was 23 years (range 17-35). The mean $\mathrm{FEV}_{1}$ was $54 \%$ predicted (range 24-98) with mean absolute values of 2.1 litres (range 0.8-3.95). Of the 27 patients, 18 used oral bronchodilators, 23 inhaled bronchodilators, and 12 inhaled steroids.

\section{MAXIMUM CHANGES}

The mean baseline values of VAS scores and $\mathrm{FEV}_{1}$ were not significantly different for the three solutions. There were significant mean (SE) baseline to maximum falls in percentage predicted $\mathrm{FEV}_{1}$ of 7.2 (1.0), 6.4 (0.6), and 5.5 (0.7) and maximum increases in VAS scores of 6.6 (3.0), 10.8 (3.0), and 8.6 (2.3) for the hypertonic, isotonic, and hypotonic solutions, respectively. However, there were no differences in the magnitude of these changes between the solutions (table 1). The maximum fall in $\mathrm{FEV}_{1}$ occurred at different time points for each solution: 7.8 (2.1), 19.2 (5.5), and 34.2 (5.9) $\mathrm{min}$ for the hypertonic, isotonic, and hypotonic solutions, respectively (fig 1). The time to the fall was significantly different between the solutions with a mean difference (95\% CI) between the hypotonic and hypertonic solutions of 28.04 (14.6 to 41.5 ) min, between the isotonic and hypertonic solutions of 12.0 ( -0.1 to 24.1 ) $\mathrm{min}$, and between the hypotonic and isotonic solutions of 15.6 (1.8 to 29.4$) \mathrm{min}$. There were no differences in the VAS scores between the solutions.

RELATIONSHIP BETWEEN MAXIMUM FALL IN FEV $_{1}$ (\% PREDICTED) AND TONICITY, VAS AND BASELINE $\mathrm{FEV}_{1}$ (\% PREDICTED)

For the maximum fall in $\mathrm{FEV}_{1}$ there were positive correlations between hypertonic and isotonic solutions $(r=0.62, \mathrm{p}<0.001)$ and between isotonic and hypotonic solutions $(r=$

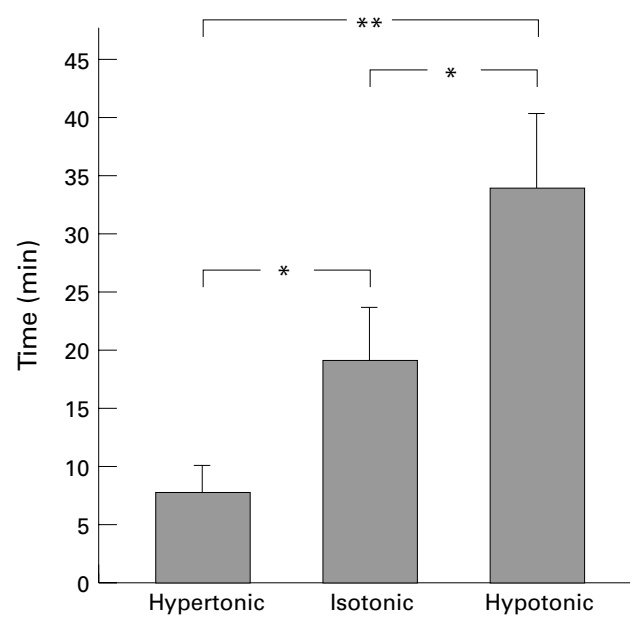

Figure 1 Mean (SE) time to maximum fall in FEV predicted) for hypertonic, isotonic, and hypotonic solutions. $* p<0.05 ; * * p<0.001$. 
$0.64, p<0.001)$. No relationship was observed between hypertonic and hypotonic solutions. This indicates that the maximum fall in $\mathrm{FEV}_{1}$ induced by the isotonic solution reflects similar falls by the hypertonic and hypotonic solutions. No correlation was found between the maximum fall in $\mathrm{FEV}_{1}$ and the increase in the VAS score which suggests that the decrease in lung function was not associated with perception of chest tightness. There was no correlation between the maximum fall in $\mathrm{FEV}_{1}$ and baseline $\mathrm{FEV}_{1}$ for any solution.

\section{PREFERRED SOLUTION}

There was no significant difference for the preference of any solution, four patients preferring the hypertonic solution, eight the isotonic solution, and 11 the hypotonic solution. The remaining four patients had no preference. The order in which the solutions were inhaled did not influence preference.

\section{Discussion}

The results of this study show that all three tonicities of colistin cause equal symptoms of chest tightness and reduction in lung function. The hypothesis that the isotonic solution would not induce bronchoconstriction was not therefore supported. Chua et al studied different antibiotics of varying tonicity and reported a fall in percentage predicted $\mathrm{FEV}_{1}$ with all solutions but a greater fall in $\mathrm{FEV}_{1}$ with hypertonic ticarcillin than with hypotonic tobramycin or isotonic saline. ${ }^{6}$ The tonicity of that hypertonic solution $(3080 \mathrm{mmol} / \mathrm{kg})$ was greater than the hypertonic solution $(415 \mathrm{mmol} / \mathrm{kg})$ in our study and may have accounted for the difference. Schoeffel et al showed a greater fall in $\mathrm{FEV}_{1}$ with increasing tonicity of saline. ${ }^{10}$ In agreement with our study, their patients also showed a fall with the hypotonic solution. Non-isotonic solutions are known to cause release of histamine by changing the osmotic load around mast cells. ${ }^{10}$ In contrast to our findings, Schoeffel et al found no reduction in $\mathrm{FEV}_{1}$ with isotonic saline. Colistin causes mast cell degeneration in vitro which may account for the bronchoconstriction induced by the isotonic solution in our study. ${ }^{12}$ The $\mathrm{pH}$ of the solutions did not vary and colistin is preservative free, therefore excluding these factors as possible mechanisms of bronchoconstriction.

In this study all bronchodilators were withheld and all patients showed a fall in $\mathrm{FEV}_{1}$ with all the solutions. The long term effect of repeated bronchoconstriction is not known. If nebulised colistin is recommended to ensure improved disease control, it is important to protect against bronchoconstriction. Salbutamol has been shown to be more effective than sodium cromoglycate, possibly through its bronchodilator activity in addition to inhibition of mast cell degranulation. ${ }^{13}$

All patients perceived an increase in chest tightness for all solutions but, as in previous studies, there was no correlation between the maximum change in $\mathrm{FEV}_{1}$ and VAS scores. ${ }^{89}$ The reasons for patients preferring a particular tonicity are difficult to determine. There was a tendency for patients not to prefer the hypertonic solution. When the hypertonic solution was compared with the other solutions in the group as a whole the fall in $\mathrm{FEV}_{1}$ occurred earlier after inhalation. For some patients an immediate fall in $\mathrm{FEV}_{1}$ may be less tolerable than an equivalent fall which occurs gradually over a longer time period such as occurred with the hypotonic solution. In our previous study maximum bronchoconstriction occurred immediately after inhalation in most patients and may therefore be a reason for the intolerance of the hypertonic solution. ${ }^{5}$

Patients with cystic fibrosis require a demanding programme of self care and adherence to any treatment is likely to be influenced by benefits and adverse symptoms. It is therefore important to measure and minimise any adverse effects of aerosol therapy before prescription of the drug.

We have shown that all tonicities of colistin cause chest tightness and bronchoconstriction. but the patients' preference varied. In the clinical setting it is impractical to challenge every patient to each tonicity. Since all tonicities cause chest tightness, prior spirometric testing before and after inhalation at intervals up to 30 minutes is recommended before prescription. The isotonic solution used as a challenge will indicate a fall in $\mathrm{FEV}_{1}$ representative of the other solutions. The fall in $\mathrm{FEV}_{1}$ for the hypotonic solution occurred over a longer time period and may be considered an alternative choice if the isotonic solution is not tolerated.

1 Hodson ME, Penketh ARL, Batten JC. Aerosol carbenicillin and gentamicin treatment of Pseudomonas aeruginosa infection in patients with cystic fibrosis. Lancet 1981;ii: 1137-9.

2 Littlewood JM, Miller MG, Ghonheim AT, Ramsden CH Nebulised colomycin for early pseudomonas colonisation in cystic fibrosis. Lancet $1985 ; \mathrm{i}: 865$.

3 Valerius NH, Koch C, Hoiby N. Prevention of chronic Pseudomonas aeruginosa colonisation in cystic fibrosis by early treatment. Lancet 1991;338:725-6.

4 Touw DJ, Brimicombe RW, Hodson ME, Heijerman HJM, Bakker W. Inhalation of antibiotics in cystic fibrosis. Eur Respir f 1995;8:1594-604.

5 Maddison J, Dodd M, Webb AK. Nebulised colistin causes chest tightness in adults with cystic fibrosis. Respir Med chest tightness

6 Chua HL, Collis GG, Le-Souef PN. Bronchial response to nebulised antibiotics in children with cystic fibrosis. Eur nebulised antibiotics in

7 Abbott J, Dodd M, Bilton D, Webb AK. Treatment compliance in young adults with cystic fibrosis. Thorax 1994, 49:115-20.

8 Rubinfield AR, Pain MCF. Perception of asthma. Lance 1976;882-4.

9 Konig P, Rejent A. Subjective and objective means of assessing cystic fibrosis and asthma. Ann Allergy 1982;49. $86-91$.

10 Schoeffel RE, Anderson SD, Altounyan REC. Bronchial hyperreactivity in response to inhalation of ultrasonically nebulised solutions of distilled water and saline. $B M F$ 1981;283:1285-7.

11 Knudson RJ, Lebowitz MD, Hollberg CJ, Burrows B. Changes in the normal maximum expiratory flow volume curve with growth and ageing. Am Rev Respir Dis 1983; 127:725-34.

12 Jasani B, Kreil B, Mackler BF, Stanworth DR. Further studies on the stuctural requirements for polypeptidestudies on the stuctural requirements for polypeptide-
mediated histamine release from rat mast cells. Biochem mediated histamine

13 Chua HL, Walker SL, LeSouef PN, Sly PD. Comparison of efficacy of salbutamol and sodium cromoglycate in the prevention of ticarcillin-induced bronchoconstriction. Pediatr Pulmonol 1993;16:311-5. 